University of South Florida

DIGITAL COMMONS

Digital Commons @ University of

@ UNIVERSITY OF SOUTH FLORIDA

South Florida

USF St. Petersburg campus Faculty

Publications

USF Faculty Publications

2019

\title{
From Journal Selection to Open Access: Practices among Academic Librarian Scholars
}

Tina Neville

University of South Florida St Petersburg, neville@mail.usf.edu

Camielle Crampsie

University of South Florida St. Petersburg, ccrampsie@mail.usf.edu

Follow this and additional works at: https://digitalcommons.usf.edu/fac_publications

Part of the Scholarly Communication Commons, and the Scholarly Publishing Commons

\section{Recommended Citation}

Neville, T., \& Crampsie, C. (2019). From Journal Selection to Open Access: Practices among Academic Librarian Scholars. portal: Libraries and the Academy, 19(4), 591-613. doi:10.1353/pla.2019.0037

This Article is brought to you for free and open access by the USF Faculty Publications at Digital Commons @ University of South Florida. It has been accepted for inclusion in USF St. Petersburg campus Faculty Publications by an authorized administrator of Digital Commons @ University of South Florida. For more information, please contact digitalcommons@usf.edu. 


\begin{abstract}
Academic librarians were surveyed about their open access publishing practices. This analysis explores approaches to journal selection, awareness of open access options, and self -archiving practices. In this study $50 \%$ considered free open access when selecting a potential journal for publication but fit to the topic and peer review were higher priorities. Findings indicate that although many librarians are publishing in open access journals or taking advantage of institutional repositories there are still barriers including article processing charges, the tenure and promotion culture, and uncertainty around intellectual property rights.
\end{abstract}

\title{
Introduction
}

When considering potential journals for manuscript submissions, faculty often place a high priority on impact factors and other metrics deemed important for tenure and promotion, while publishing in open access (OA) journals often takes a back seat. Academic librarians are known for their promotion of the open access movement and often have entire positions dedicated to educating university faculty on the advantages of open access, providing guidance on negotiating for better access in copyright agreements, and other related services. But do they practice what they preach? Additional information on academic librarian authors' approaches to journal selection seems warranted. This study will address the following questions:

- What do academic library practitioners consider when selecting specific avenues for journal publication?

- Are academic librarians aware of their own open access options? Are they negotiating with journal publishers for enhanced intellectual property rights?

- Are academic librarians using open access options to set an example for other scholars? 


\section{Literature review}

\section{Journal selection}

When selecting a journal appropriate for submission of a manuscript, many factors may be

considered including, scope, audience, prestige, timeliness, acceptance rate, and more. ${ }^{1}$ No single consideration dominates librarians' choice for journal submission. Like faculty in many disciplines, academic librarians often indicate their greatest concern when selecting a journal is getting it published in a title that will have value for tenure and/or promotion. ${ }^{2}$ Dalton adapted Björk and Holmström's journal selection model to categorize LIS author priorities into four areas: prestige, readership, performance, and infrastructure. ${ }^{3}$ For some, open access options are also a consideration in journal selection. ${ }^{4}$

\section{Open access}

Open access in its purest form is “... the free, immediate, online availability of research articles coupled with the rights to use these articles fully in the digital environment." In addition to the philosophy of providing free access to information, choosing to publish an article as open access can provide a number of additional advantages including greater visibility leading to more citations, the chance to reach a broader audience and, in some cases, the option to get the information published online more quickly. ${ }^{6}$

Ideally, open access journals would not require payment by either authors or readers. However, because of costs for production, many open access journals are unable to operate according to this model. Some publishers now provide an option for the author or their funding agency to pay an article processing charge (APC) to the publisher. This allows immediate access to all readers, 
even those without a paid subscription (often called gold open access). Other publishers provide options for self-archiving whereby an author can publish a pre- or post-print of the manuscript on a personal website or an institutional or subject repository (green open access). In fact, as of February 2019, 81\% of 2562 publishers contained in the SHERPA RoMEO database allow the self-archiving of pre- or post-prints. ${ }^{7}$ Unfortunately, the green option often includes an embargo period of anywhere from six months to several years before the document is legally allowed to be freely available.

A number of research studies have analyzed how readily these green and gold open access models are being adopted by academic librarians or by researchers in other disciplines. ${ }^{8}$ An analysis of articles published by academic librarians in 2008, found that approximately $49 \%$ were available in an open access format but $58 \%$ were eligible to be posted as open access in a repository and, after the normal embargo periods, $94 \%$ were qualified for open access. ${ }^{9}$ Laakso conducted an extensive study of 1,150,827 multidisciplinary articles published in 2010 in an attempt to see how many would allow self-archiving if all authors took advantage of that option. His analysis showed that $65 \%$ of the accepted manuscripts could be uploaded immediately. This increases to $79 \%$ after a 12 -month embargo period. ${ }^{10}$ In a study of more than 1000 articles published in the top 20 LIS journals in 2013, the authors found that approximately $28 \%$ of the articles were available in an open access format. Of those, approximately $28 \%$ were located in institutional repositories though most of the repositories were at institutions outside of the United States. $^{11}$ 
Gold access requiring authors to pay a fee appears to be slow to gain acceptance. In a large survey of authors publishing in Taylor and Francis publications, only about a third had selected the gold publishing option. ${ }^{12}$ A study of articles published since 2010 on the topic of open access, assumed that these authors would be more likely to select an open access journal for their publication. That analysis discovered that $32 \%$ of the articles were published as gold open access and $28 \%$ were available as green open access. ${ }^{13}$

Although there appears to be an upward trend in open access acceptance, availability and widespread adoption of true open access journals is still somewhat limited ${ }^{14}$ Research funding agencies are beginning to push back on paywalled journals, contending that research sponsored by public agencies should be available to all. This philosophy was implemented as early as 2008 with the National Institutes of Health (NIH) Public Access Policy requiring all authors who received NIH funding to publish an open access version of their peer-reviewed article in PubMed Central. ${ }^{15}$ The NIH policy allows for up to a 12-month embargo; however, cOALition S, an open access initiative endorsed by international funding agencies including Wellcome Trust and the Bill and Melinda Gates Foundation, will only allow publication in titles that allow immediate open access. ${ }^{16}$

Article processing charges, whether paid by the authors, an institution, or a funding agency, remain a significant concern, although some universities provide funding to help an author pay the fees. ${ }^{17}$ Almost $40 \%$ of North American LIS faculty listed APC fees as the reason they have not published in an open access journal. ${ }^{18}$ There is some question as to why professional associations do not provide free open access as a service to their profession. An analysis of five 
American Library Association (ALA) scholarly journals illustrates the business challenges publishers see when attempting to provide an open access journal. Even with a dedicated volunteer editorial board, these associations need to find a place to house the journal, and locate some level of revenue to create a sustainable, stable platform for the future. ${ }^{19}$

There is also concern over the potential lack of acceptance by promotion and tenure committees, and whether open access journals are considered of equal value to established fee-based titles. ${ }^{20}$ A study of LIS faculty in North America found that $44 \%$ felt that articles published in open access journals would be viewed less favorably by tenure committees. ${ }^{21}$ Many open access journals are relatively new and have not had time to develop a reputation within a discipline or to establish an impact factor. ${ }^{22}$ Librarians who have attained tenure may be more open to publishing in open access venues. As one respondent noted in a 2012 survey, "Now that I have tenure, I'm able to target open access publishing... and now (sic) worry as much about the impact of my publication record on my ability to be promoted." 23

\section{Advocating for better intellectual property rights}

Another barrier is the lack of knowledge about publisher's policies on self-archiving. ${ }^{24}$ In a study of European authors from a variety of disciplines, more than two-thirds of the respondents found it difficult to determine whether they had the right to place their article in a repository. There was confusion over copyright licenses with the perception that figuring out author's rights was "tedious" and "time-consuming." 25 In some disciplines there is distrust over using a pre- or postprint version, wanting to rely on the publisher's final version for research purposes. ${ }^{26}$ 
A 2005 study of academic research librarians, found that only eleven of 140 respondents had tried to negotiate for better intellectual property rights with ten of the eleven being successful. ${ }^{27}$ A 2011 survey of faculty with NIH funding, found 97.8\% sign copyright agreements "as is" potentially causing conflict with the NIH mandatory PubMed policy. ${ }^{28}$ Questioning the standard copyright license offered by many publishers helps send the message that overall reform is needed.

\section{Librarians as open access champions}

Several years ago, Bowley and Vandegrift issued a "call for librarians to practice what we preach, regardless of, or even in the face of, tenure and promotion 'requirements,' long-held professional norms, and the unnecessary fear, uncertainty and doubt that controls academic publishing." ${ }^{29}$ Many see personal responsibility and getting information out to researchers who don't have subscription access as important reasons for adding materials to a repository. ${ }^{30}$ However, several studies agree that librarians, at least in North America, may tend to talk the talk but are not necessarily following through with their own publications when it comes to open access. ${ }^{31}$ In an analysis of LIS articles published between 2003 and 2013 on the topic of open access, only $19 \%$ of the articles were self-archived indicating that, when the responsibility for making a publication open is left up to the author, even those who are presumably knowledgeable about the process, they don't necessarily follow-through. ${ }^{32}$ A study of Canadian LIS faculty found that, although $69 \%$ stated that the high cost of journal subscriptions was a

detriment to research, only $23 \%$ attempted to publish their own works in affordable journals. ${ }^{33}$

\section{Methods}


The population being studied here is limited to practicing academic librarians which, for the purposes of this study, is defined as those librarians holding an MLS degree and working in an academic library but who do not devote the majority of their time to teaching in a graduate LIS program. The publishing expectations and experiences of LIS faculty and academic library practitioners may be very different so this study is limited to practicing academic librarians in North America.

An online survey was created using a Google Docs form and distributed to a variety of academic librarian discussion lists (Association of College and Research Libraries (ACRL) University Libraries list, state chapter lists for ACRL or academic libraries, Canadian Association of Research Libraries (CARL) list, etc.). The survey instrument consisted of demographic, quantitative, and Likert scale questions with all questions including an opportunity for comment. A number of questions on the survey were adopted from previous studies to allow for direct comparisons. ${ }^{34}$ The survey was distributed in November 2017 and remained open for three weeks. All responses were anonymous and were downloaded into an Excel spreadsheet for analysis.

It is unknown how much the opinions provided here are representative of the overall academic library profession. Although a major attempt was made to get the survey out to as many academic library practitioners as possible, there was no control over the self-selection of the respondents, many of whom were undoubtedly interested in the topic and had strong feelings about publishing and open access. In constructing the survey questions, an attempt was made to list question options in a random or categorized order; however, question order may have played a role in responses. The responses were anonymous so there is no way to determine which institutions are represented and how well they are balanced with the full academic library population. 


\section{Findings and Discussion}

Two hundred and fifteen academic library practitioners responded to the survey. Ninety-three percent of the respondents were from the United States, $6 \%$ were from Canada, and one respondent was from Central America. Although the definition of faculty status often varies from one institution to another, $79 \%$ of the respondents are considered faculty. The survey respondents are relatively evenly divided between experienced faculty (54\% associate or full professors and $51 \%$ with more than ten years of experience) and junior faculty (45\%, assistant professor or other, and $49 \%$ with ten or fewer years of experience). When examining institutional composition, most respondents work in a doctoral granting institution (80\%) with more than 10,000 students $(73 \%)$. [insert table 1]

\section{Journal selection}

Survey participants were asked to consider what criteria were important when selecting an appropriate journal for submission of a manuscript. Respondents were able to select more than one option for consideration. The top three choices were: 1) scope and fit to the topic, 2) whether the journal is peer reviewed, and 3) the intended audience. This corresponds well to Dalton's study where library researchers and practitioners selected peer review as the most important consideration when it comes to prestige, and topical fit as the most important criterion in the readership category. ${ }^{35}$ In the current study, when asked to narrow their selections down to the most important consideration in journal selection, scope and fit was selected by nearly half of the respondents (49\%). Fifty-nine percent of the respondents are required to publish peer reviewed articles for promotion or tenure and an additional $31 \%$ have a recommendation to publish in peer 
reviewed journals. Considering the tremendous importance of peer review to the careers of the majority of the respondents it is somewhat surprising that only $21 \%$ chose this as the most important consideration. It may be that peer review is so important that many academic librarians don't even consider journals that are not peer reviewed. [insert table 2]

Relating to journal prestige, impact factors or similar rankings were only considered important by $18 \%$ of the survey respondents in this study. This was lower than anticipated considering that $45 \%$ of the respondents were from Association of Research Libraries (ARL) or Canadian Association of Research Libraries (CARL) institutions and an additional 36\% were from other doctoral universities, institutions that often place high value on these metrics. In a 2016 study of LIS faculty, $80 \%$ of the respondents considered the journal's impact factor to be very important or important. ${ }^{36}$ Although $65 \%$ of the current respondents are in tenure-track positions, this survey was limited to academic librarian practitioners who may have different publishing expectations than LIS faculty researchers. Differing perspectives between LIS researchers and practitioners is supported in Dalton's study which found a statistical difference between these groups when asked about the importance of journal impact factors. ${ }^{37}$ [insert table 3]

\section{Open access}

In this study, $50 \%$ considered free open access when selecting a potential journal for publication with $6 \%$ of the respondents considering that as their top consideration. However, gold open access options appear to be less acceptable with only $10 \%$ of the respondents even considering that option when selecting a journal. In spite of efforts by libraries and universities to help authors with funding open access fees it appears that APCs remain a barrier. Three percent of the 
respondents in this study are at institutions that provide full funding for open access fees and an additional $23 \%$ can get partial funding. However, $64 \%$ have no funding for APCs and $10 \%$ of the respondents commented that they didn't think anyone at their institution had even thought to apply for author fees. In addition, several commented that their institution had attempted to help with author fees but funding was limited or had been cut off for budgetary reasons. A very large $(n=11,927)$, international study of multi-disciplinary authors in 2013 found that $19 \%$ of the respondents worked at institutions that always or often paid the entire OA fee and $22 \%$ worked at places where they always or often received partial funding for OA fees. ${ }^{38}$ This leads to a question of whether institutions in other countries are more apt to help with publication fees or if they are at institutions other than universities where payment is an accepted part of the process.

Promotion and tenure concerns may play a role in open access considerations as indicated by respondent's comments on their conflict between philosophy and reality: "At this point in my career, I'd like to consider some of these other factors when choosing a journal. But my priority right now is just getting the darn thing peer reviewed and published." Another commented, "I believe strongly in open access (that my success in tenure is not aligned with my personal philosophy gives me the desire to continue writing after continuing appointment and direct my writing at that point to open access journals)." [insert tables 4 and 5]

\section{Advocating for better intellectual property rights}

In spite of many librarians' familiarity with the scholarly publication process, there remains confusion by some on the publisher's policies relating to self-archiving. Lack of understanding of these policies (44\%) was second only to time constraints (46\%) as the 
main reasons why respondents in this study were not self-archiving. Although $81 \%$ of the respondents work at an institution with an institutional repository, only $29 \%$ were aware of a formal policy on open access. Fifteen percent were not sure if there was an open access policy, another indication of the lack of visibility of the OA movement even within the library profession. This lack of clarity can have a detrimental effect on the open access movement. A study of European authors from a variety of disciplines, noted that, when authors are unclear about their copyright permissions, they assumed that their self-archiving rights were more restrictive than they really were. ${ }^{39}$ [insert table 6]

Although a number of large funding agencies require their sponsored publications to be added to subject repositories, only $39 \%$ of the respondents in this study have added their content to repositories outside of their own institution. ${ }^{40}$ Perhaps the main reason however, is the lack of an established subject repository specific to library and information science. A recent article mentions the LIS Scholarship Archive (LISSA) and several respondents to this survey have added content to e-LIS, yet neither of these resources appear to have reached major visibility among librarians. ${ }^{41}$ Other survey participants commented that they participate in ResearchGate or Academia.edu; however, these organizations are not normally considered to be true open access repositories. ${ }^{42}$

If journal publishers as a whole are not prepared to offer stronger open access options, are library faculty attempting to negotiate for better copyright options with each submission? The ability to retain copyright ownership was considered important by $41 \%$ in this study. This appears to be an increase from a previous study that found that open access options and retaining copyright were 
slightly less important, being ranked between 2 and 3 on a 5-point scale. ${ }^{43}$ Many academic librarians need to publish in high impact journals for tenure and promotion but may hesitate to negotiate for fear that the manuscript will be rejected. A 2005 survey of academic librarians found that only $7 \%$ of the respondents had attempted to negotiate for better intellectual rights. ${ }^{44}$ Rowlands found that $55 \%$ of the North American authors from a variety of disciplines had no interest in negotiating for better copyright permissions. ${ }^{45}$ In this study $21 \%$ of the respondents had tried for better copyright with $74 \%$ of those being successful. But, for many, publication still trumps open access.

\section{Librarians as open access champions}

It would appear that many librarians are practicing what they preach regarding OA by adding their content to their institutional repositories. In this study $76 \%$ regularly add their accepted manuscripts to their institution repository if it is permitted by copyright. This is a higher percentage than a previous study by Emery who reported a green open access deposit rate of only $22 \% .{ }^{46}$ Eighty-four percent of the participants in the current study who deposited in their IR did so because of a feeling of responsibility, which may account for the higher participation.

However, if the results of this survey are any indication, some librarians are still not convinced that open access or self-archiving is worth the time and effort. A number of comments indicated a lack of interest or motivation: "Could add the pre-prints, I guess, not that interested," "I know I should care more about open access than I do...," "It's just not a part of our institutional culture," and "I just do not care enough to take the time to submit items to the repository." Several others mentioned that, since they had selected open access publications, there was no need to add them 
to their repository. And, one librarian seems to have missed the philosophy of open access entirely, commenting, "I don't care because it's published elsewhere."

\section{Conclusion}

In this study of academic librarians, the top criteria for journal selection were the fit or scope of the topic and whether a journal is peer reviewed. Once those conditions are met, librarians begin to consider secondary features such as publisher reputation and open access options. Impact factors and acceptance rates did not play a major role when selecting a journal. This was somewhat surprising considering the large majority of respondents were in tenured or tenuretrack positions at doctoral universities. In addition, the respondents were primarily from the United States. It would be interesting to see if the attitudes observed here also hold true in other countries. Few studies on journal selection priorities have been conducted recently and it would be interesting to replicate this study to a broader and more international audience.

Many academic librarians in North American are consciously trying to practice what they preach by publishing in open access journals or adding their pre- or post-print copies to their institutional repositories. That said, areas for improvement remain. Comments indicate that there is still a lot of confusion over what publishers allow when it comes to archiving. More than seven years ago, Mercer suggested that negotiating for better author rights might be worth adding to the LIS curriculum. ${ }^{47}$ This would be useful not only for librarians as authors but also for academic librarians to gain confidence when educating faculty about open access issues. It would be interesting to know if any library schools have taken this advice and, if so, if it will lead to greater author advocacy in the future. Once an author has published in an open access 
publication they are significantly more likely to publish open access again and are also more likely to deposit their work in a repository. ${ }^{48}$ How then, do we convince librarian authors of the need to lead by example?

Tenure and promotion criteria continue to need clarification as to whether open access publications will be considered in the same light as traditional, fee-based journals. Peekhaus noted that "there appears to be a disconnect between survey participants' support for unhindered access to research and their own publishing practices, which tend to remain informed and constrained by the parameters of the academy's traditional reward structure. ${ }^{\prime 49}$ An interesting follow-up study could analyze academic library practitioner's tenure and promotion guidelines to see if open access publications are addressed. Although there has been progress, there remains a need to make open access options more straight-forward, visible, and a higher priority in the field of academic librarianship.

\section{Appendix A: Survey Questions}

Note: The data used in this article were taken from a larger survey. The relevant questions to this study are listed below. All questions allowed for comments. Some of the questions were adopted from:

Dalton, Michelle. "A Dissemination Divide? the Factors that Influence the Journal Selection Decision of Library \& Information Studies (LIS) Researchers and Practitioners." Library and Information Research 37, no. 115 (2013): 33-57.

Frass, Will, Jo Cross, and Victoria Gardner. Open Access Survey: Exploring the Views of Taylor \& Francis and Routledge Authors, 2013.

Frass, Will, Jo Cross, and Victoria Gardner. Taylor \& Francis Open Access Survey: June 2014: Taylor \& Francis Group, 2014.

Peekhaus, Wilhelm and Nicholas Proferes. "How Library and Information Science Faculty Perceive and Engage with Open Access." Journal of Information Science 41, no. 5 (2015): 640661. doi:10.1177/0165551515587855.

Rowlands, Ian and David Nicholas. "Scholarly Communication in the Digital Environment: The 2005 Survey of Journal Author Behaviour and Attitudes." Aslib Proceedings 57, no. 6 (2005): 481-497. doi:10.1108/00012530510634226. 
Swan, Alma and Sheridan Brown. Open Access Self-Archiving: An Author Study. Cornwall, UK: Key Perspectives Limited, 2005.

Do you hold an MLS from an ALA accredited library school (or equivalent)?

- Yes

- $\quad$ No (end survey)

Please select the option that best fits your current position

- Academic Library practitioner (For the purposes of this study, an academic library practitioner is defined as a person holding at least an MLS degree who provides reference, collection development, archival, technical services, administrative, or other student and faculty support services in a college or university library. The practitioner may teach courses as an adjunct professor but that is not their primary responsibility.)

- Library School Faculty (For the purposes of this study, defined as a person who spends the majority of their working hours teaching graduate MLS students.) (end survey)

- None of the above (end survey)

Approximately how long have you been an academic librarian practitioner (combined number of years if you have changed positions)

- Less than one year

- 1-2 years

- 3-5 years

- 6-10 years

- 11-20 years

- More than 20 years

Your current faculty status (please select the best fit)

- Professional or Administrative, not Faculty

- Faculty, tenure-track (or continuing contract), not yet tenured

- Faculty, tenured (or continuing contract)

- Faculty, promotion earning but no options for tenure or continuing contract

- Faculty, no options for promotion within the position

- Other

Your current academic rank (please select the best fit):

- Full Librarian / Full Professor (or equivalent)

- Associate Librarian / Associate Professor (or equivalent)

- Assistant Librarian / Assistant Professor (or equivalent)

- Instructor Librarian (or equivalent)

- Visiting Librarian (or equivalent)

- Other

Approximately how long have you held your current rank?

- Less than one year

- One-two years

- Three-five years 
- More than five years

What is your current age?

- Younger than 18 (end survey)

- $18-21$

- 22-25

- 26-30

- 31-35

- $36-40$

- $41-45$

- $46-50$

- $51-55$

- 56-60

- 61-65

- 66-70

- Over 70

- Prefer not to answer

Location of your current institution

- USA

- Canada

- Mexico

- Central America

- South America

- Europe

- Asia

- Africa

- Australia

- Other

Please describe your current college or university:

- Doctoral granting, ARL or CARL Member

- Doctoral granting, not a member of ARL or CARL

- Master's level only (no doctoral degrees offered)

- Baccalaureate level only (no graduate degrees offered)

- Associate or professional degrees only (no baccalaureate or graduate degrees offered)

- Other

Size of your current institution (head count)

- Less than 1000 students

- 1000 - 2000 students

- 2001 - 5000 students

- 5001 - 10,000 students

- $10,001-20,000$ students

- More than 20,000 students

Approximately how many professional librarians (holding an MLS) are there at your library? If you have multiple libraries within your institution, please provide the number in your building. 
- $1-5$

- $6-10$

- $11-15$

- $16-20$

- $20-25$

- More than 25

Is publication of peer reviewed journal articles important for promotion or tenure (or continuing contract) at your current institution?

- Yes, Required

- Yes, Recommended

- No, we are promotion or tenure earning but it is not considered for librarians

- N/A, we are not promotion or tenure earning

Is publication in peer reviewed journals important for annual performance evaluations at your current institution?

- Yes, Required

- Yes, Recommended

- No, we have annual performance evaluations but peer reviewed articles aren't considered for librarians

- N/A, we don't have annual performance evaluations

Counting those which are in press, have you published any PEER REVIEWED journal articles within the last ten years?

- Yes

- No (end survey)

When selecting a journal title for submission what do you consider? (Please check all that apply)

- Publisher reputation

- Positive prior experiences with the editor

- Scope and fit to topic

- Intended audience

- Indexed in a subject-specific database

- Size of readership / number of journal subscribers

- Online availability

- Impact factor or ranking in SCImago or similar lists

- Acceptance rate

- Estimated time from submission to publication

- Frequency of publication

- Whether the journal is peer reviewed

- Type of peer review (blind, double-blind, etc.)

- Publication fees

- Ability to retain copyright

- Availability of free open access (posting of pre-print, post-print or full article after no or brief embargo

- Availability of open access rights for a fee 
- Manuscript length allowed

- Citation style used

- Co-author's preference

When selecting a journal title for submission, what do you consider to be the MOST IMPORTANT factor in making your decision?

- Publisher reputation

- Positive prior experiences with the editor

- Scope and fit to topic

- Intended audience

- Indexed in a subject-specific database

- Size of readership / number of journal subscribers

- Online availability

- Impact factor or ranking in SCImago or similar lists

- Acceptance rate

- Estimated time from submission to publication

- Frequency of publication

- Whether the journal is peer reviewed

- Type of peer review (blind, double-blind, etc.)

- Publication fees

- Ability to retain copyright

- Availability of free open access (posting of pre-print, post-print or full article after no or brief embargo

- Availability of open access rights for a fee

- Manuscript length allowed

- Citation style used

- Co-author's preference

Does your institution have a formal policy on open access?

- Yes

- No

- Not sure

Does your institution provide funding for open access?

- Yes, all funding

- Yes, partial funding

- To my knowledge, no one has ever pursued it

- No

- I'm not sure

Does your institution have an institutional repository for faculty publications?

- Yes

- No

- Not sure 
If you have an institutional archive do you regularly add your accepted manuscripts to the IR, if allowed by copyright?

- Yes

- No

Have you ever deposited any of your work into an open access repository outside of your own institution?

- Yes

- No

If you have deposited publications in a repository of any type, what was your incentive? (Please check all that apply)

- Personal responsibility to make my work freely available

- Provides greater exposure to my works which will aid my career

- Requests for my publication by researchers who can't access it at their institution

- An institutional requirement to deposit my publication

- A publisher offer to deposit my publication on my behalf

- A funder requirement to deposit my publication

- A colleague's encouragement to deposit my publication

- A repository manager's offer to deposit my publication on my behalf

If you decided NOT to deposit your publication in a repository, what were your reasons (Please check all that apply)

- Lack of understanding about the publisher's policy on repositories

- Lack of time available to engage with repositories

- Lack of technical understanding on how to upload to a repository

- Concerns about the discoverability of content within the repository

- Concerns about the longevity of the repository

- Lack of appropriate disciplinary repository available

Have you ever tried to negotiate for better intellectual property rights with a publisher?

- Yes

- No

Were you successful in negotiating better property rights?

- Yes

- No

\section{Notes}

1. Chang, Yu-Wei. "Comparative Study of Characteristics of Authors between Open Access and Non-Open Access Journals in Library and Information Science." Library \& Information Science Research 39, no. 1 (2017): 9, https://doi.org/10.1016/j.lisr.2017.01.002; Dalton, Michelle. "A Dissemination Divide? The Factors that Influence the Journal Selection Decision of Library \& Information 
Studies (LIS) Researchers and Practitioners." Library and Information Research 37, no. 115 (2013): 44-5; Peekhaus, Wilhelm and Nicholas Proferes. "An Examination of North American Library and Information Studies Faculty Perceptions of and Experience with Open-Access Scholarly Publishing." Library \& Information Science Research 38, no. 1 (2016): 22, https://doi.org/10.1016/j.lisr.2016.01.003; Rowlands, Ian and David Nicholas. "Scholarly Communication in the Digital Environment: The 2005 Survey of Journal Author Behaviour and Attitudes." Aslib Proceedings 57, no. 6 (2005): 483, https://doi.org/10.1108/00012530510634226; Rowlands, Ian, Dave Nicholas, and Paul Huntington. "Scholarly Communication in the Digital Environment: What do Authors Want?" Learned Publishing no. 17 (2004): 262-4; Sugimoto, Cassidy R., Andrew Tsou, Sara Naslund, Alexandra Hauser, Melissa Brandon, Danielle Winter, Cody Behles, and S. C. Finlay. "Beyond Gatekeepers of Knowledge: Scholarly Communication Practices of Academic Librarians and Archivists at ARL Institutions." College \& Research Libraries 75, no. 2 (2014): 152-3.

2. Carter, Howard, Carolyn A. Snyder, and Andrea Imre. "Library Faculty Publishing and Intellectual Property Issues: A Survey of Attitudes and Awareness." Portal: Libraries \& the Academy 7, no. 1 (2007): 74; Peekhaus and Proferes, "Examination of North," 22.

3. Björk, Bo-Christer and Jonas Holmström. "Benchmarking Scientific Journals from the Submitting Author's Viewpoint." Learned Publishing 19, no. 2 (2006): 147-155; Dalton, "Dissemination Divide, 36, 38."

4. Bosah, Gabriel, Chuma Clement Okeji, and Ebikabowei Emmanuel Baro. "Perceptions, Preferences of Scholarly Publishing in Open Access Journals: A Survey of Academic Librarians in Africa." Digital Library Perspectives 33, no. 4 (2017): 387, https://doi.org/10.1108/DLP-03-2017-0011; Chang, "Comparative Study, 13”; Frass, Will, Jo Cross, and Victoria Gardner. Open Access Survey: Exploring the Views of Taylor \& Francis and Routledge Authors, (2013). 7, https://www.tandf.co.uk//journals/explore/Open-Access-Survey-March2013.pdf; Frass, Will, Jo Cross, and Victoria Gardner. Taylor \& Francis Open Access Survey: June 2014: (Taylor \& Francis Group, 2014), 17, https://www.tandf.co.uk//journals/explore/openaccess-survey-june2014.pdf; Peekhaus and Proferes, "Examination of North," 22.

5. SPARC, "Open Access," accessed February 27, 2019. https://sparcopen.org/open-access/.

6. Swan, Alma and Sheridan Brown. Open Access Self-Archiving: An Author Study. (Cornwall, UK: Key Perspectives Limited, 2005), 4-5, 10; Peekhaus, Wilhelm. "Open Access Among Canadian Library and Information Science Faculty." Canadian Journal of Information \& Library Sciences 41, no. 1 (Mar, 2017): 125.

7. SHERPA/RoMEO. "SHERPA/RoMEO Statistics," (February 27, 2019). http://www.sherpa.ac.uk/romeo/statistics.php.

8. Chaudhuri, Jayati and Sarah Baker. "Identifying Open Access Articles within the Top Ten Closed Access LIS Journals: A Global Perspective." Library Philosophy and Practice no. 1245 (2015): 1-15, https://digitalcommons.unl.edu/libphilprac/1245; Chilimo, Wanyenda Leonard and Omwoyo Bosire Onyancha. "How Open is Open Access Research in Library and Information Science?" South African Journal of Libraries \& Information Science 84, no. 1 (2018): 11-19, https://doi.org/10.7553/84-11710; Laakso, Mikael. "Green Open Access Policies of Scholarly Journal Publishers: A Study of What, When, and Where Self-Archiving is Allowed." Scientometrics no. 2 (2014): 475-494, https://doi.org/10.1007/s11192-013-1205-3; Rowley, Jennifer, Frances 
Johnson, Laura Sbaffi, Will Frass, and Elaine Devine. "Academics' Behaviors and Attitudes Towards Open Access Publishing in Scholarly Journals." Journal of the Association for Information Science \& Technology 68, no. 5 (2017): 1201-11, https://doi.org/10.1002/asi.23710.

9. Mercer, Holly. "Almost Halfway there: An Analysis of the Open Access Behaviors of Academic Librarians." College \& Research Libraries 72, no. 5 (2011): 447.

10. Laakso, "Green Open Access, 488."

11. Chaudhuri and Baker, "Identifying Open Access," 6, 9.

12. Rowley, et al., "Academics' Behaviors. 1208."

13. Schultz, Teresa. "Practicing what You Preach: Evaluating Access of Open Access Research." Journal of Electronic Publishing 21, (2018): 6, https://doi.org/10.3998/3336451.0021.103.

14. Chang, "Comparative Study," 13; Peekhaus, "Open Access Among," 116-9; Swan and Brown, Open Access Self-Archiving. 12."

15. NIH Public Access Policy Details. (National Institutes of Health., March 25, 2016). https://publicaccess.nih.gov/policy.htm

16. Else, Holly. "Radical Open-Access Plan Could Spell End to Journal Subscriptions." Nature 561, (2018): 17, https://www.nature.com/articles/d41586-01806178-7; Science Europe. "About: What is cOALition S?” (2019), https://www.coalitions.org/about/; Science Europe. "Funders and Supporters," accessed February 26, 2019. https://www.coalition-s.org/funders-and-supporters/

17. Bosah, Okeji, and Baro, "Perceptions, Preferences," 387; Elsevier Inc. "Survey Findings: Librarians, Researchers and Open Access Publishing." Library Connect, (October 25, 2017); Peekhaus, "Open Access Among," 122.

18. Peekhaus and Proferes, "Examination of North," 25.

19. Hall, Nathan, Sara Arnold-Garza, Regina Gong, and Yasmeen Shorish. "Leading by Example? ALA Division Publications, Open Access, and Sustainability." College \& Research Libraries 77, no. 5 (2016): 656-7, https://doi.org/10.5860/crl.77.5.654.

20. Carter, Snyder, and Imre, "Library Faculty Publishing," 74; Peekhaus, "Open Access Among," 121; Sugimoto, et al., "Beyond Gatekeepers," 153.

21. Peekhaus, Wilhelm and Nicholas Proferes. "How Library and Information Science Faculty Perceive and Engage with Open Access." Journal of Information Science 41, no. 5 (2015): 649, https://doi.org/10.1177/0165551515587855.

22. Bosah, Okeji, and Baro, "Perceptions, Preferences," 389; Chang, "Comparative Study, 12.

23. Sugimoto, et al., "Beyond Gatekeepers," 153.

24. Swan and Brown, Open Access Self-Archiving, 3; Frass, Cross, and Gardner, Taylor \& Francis, 14.

25. Spezi, Valérie, Jenny Fry, Claire Creaser, Steve Probets, and Sonya White. "Researchers' Green Open Access Practice: A Cross-Disciplinary Analysis." Journal of Documentation 69, no. 3 (2013): 347, https://doi.org/10.1108/JD-01-2012-0008.

26. Spezi, et al., "Researchers' Green," 352; Swan and Brown, Open Access Self-Archiving, 2.

27. Carter, Snyder, and Imre, "Library Faculty Publishing," 73. 
28. Charbonneau, Deborah H. and Jonathan McGlone. "Faculty Experiences with the National Institutes of Health (NIH) Public Access Policy, Compliance Issues, and Copyright Practices." Journal of the Medical Library Association 10, no. 1 (2013): 23.

29. Bowley, Chealsye and Micah Vandegrift. "Librarian, Heal Thyself (Pre-Reviewed Version)." In the Library with the Lead Pipe (2014), 13.

30. Frass, Cross, and Gardner, Taylor \& Francis, 13.

31. Carter, Snyder, and Imre, "Library Faculty Publishing," 77; Mercer, "Almost Halfway There," 447.

32. Chilimo and Onyancha, "How Open," 17.

33. Peekhaus, "Open Access Among," 114.

34. Dalton, "Dissemination Divide."; Frass, Cross, and Gardner, Open Access Survey; Frass, Cross, and Gardner, Taylor \& Francis; Peekhaus and Proferes, "How Library."; Rowlands and Nicholas, "Scholarly Communication...2005 Survey."; Swan and Brown, Open Access Self-Archiving.

35. Dalton, "Dissemination Divide,"44-5.

36. Peekhaus and Proferes, "Examination of North," 23.

37. Dalton, "Dissemination Divide," 46.

38. Frass, Cross, and Gardner, Open Access Survey, 16.

39. Spezi, et al., "Researchers' Green," 347.

40. See NIH Public Access; "Open Access Policy 2020," (Wellcome Trust, November 2018), https://wellcome.ac.uk/sites/default/files/wellcome-open-access-policy-2020.pdf, and "Tri-Agency Open Access Policy on Publications," (Government of Canada, December 21, 2016), http://www.science.gc.ca/eic/site/063.nsf/eng/h_F6765465.html?OpenDocument as examples.

41. Emery, Jill. "How Green is our Valley? Five-Year Study of Selected LIS Journals from Taylor \& Francis for Green Deposit of Articles." Insights: 31, (2018): 4, https://doi.org/10.1629/uksg.406; The LIS Scholarship Archive, accessed February 27, 2019, https://lissarchive.org/; e-LiS: e-prints in library \& information science, accessed February 27, 2019, http://eprints.rclis.org/

42. Fortney, Katie and Justin Gondor. A Social Networking Site is not an Open Access Repository. (University of California. Office of Scholarly Communication, December 1, 2015). https://osc.universityofcalifornia.edu/2015/12/a-social-networking-site-is-not-anopen-access-repository/.

43. Rowlands and Nicholas, "Scholarly Communication...2005 Survey," 483; Dalton, "Dissemination Divide," 44.

44. Carter, Snyder, and Imre, "Library Faculty Publishing," 73.

45. Rowlands, Nicolas, and Huntington, "Scholarly Communication," 265.

46. Emery, "How Green," 5.

47. Mercer, "Almost Halfway There," 450.

48. Peekhaus and Proferes, "How Library," 646, 651.

49. Peekhaus, "Open Access Among," 128. 